\title{
Henry James, Théophile Gautier
}

\section{Lise Sabourin}

\section{(2) OpenEdition}

\section{Journals}

\section{Édition électronique}

URL : http://journals.openedition.org/studifrancesi/3803

DOI : 10.4000/studifrancesi.3803

ISSN : 2427-5856

\section{Éditeur}

Rosenberg \& Sellier

\section{Édition imprimée}

Date de publication : 1 décembre 2012

Pagination : 593-594

ISSN : 0039-2944

\section{Référence électronique}

Lise Sabourin, «Henry James, Théophile Gautier », Studi Francesi [En ligne], 168 (LVI | III) | 2012, mis en ligne le 30 novembre 2015, consulté le 07 mars 2021. URL : http://journals.openedition.org/ studifrancesi/3803 ; DOI : https://doi.org/10.4000/studifrancesi.3803

\section{Ce document a été généré automatiquement le 7 mars 2021.}

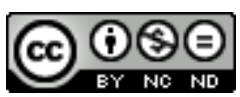

Studi Francesi è distribuita con Licenza Creative Commons Attribuzione - Non commerciale - Non opere derivate 4.0 Internazionale. 


\title{
Henry James, Théophile Gautier
}

\author{
Lise Sabourin
}

\section{RÉFÉRENCE}

HENRY JAMES, Théophile Gautier, préface de Paolo TORTONESE, traduction d'Emmanuel SAUSSIER et Myriam FATEN SFAR, Paris, Éditions Manucius, «Littéra», 2011, pp. 112.

1 Henry James, très éloigné par sa sensibilité de la théorie française de l'art pour l'art, voit en Gautier un martyr de l'idée plastique, démoralisé par le mal du siècle, mais finalement plus amoral que corrompu. Si Mademoiselle de Maupin lui paraitt en fait un roman de protestation «puérile» (p. 43), il déplore l'influence de ce «Keats francisé» (p. 50) sur Swinburne et Wilde. La primauté donnée aux sensations lui semble en effet marque d'oisiveté propice à l'indifférence au nom de l'esthétique. Cependant il reste fasciné par «le splendide talent de [cet auteur] inexorablement limité» métaphysiquement (p. 75). Sa pratique émancipée de la littérature comporte bien la «bénédiction d'une sensibilité à la beauté matérielle»(p.79) qui lui a permis de sublimer le genre descriptif, ressenti par l'Américain comme par nature restreint.

2 Aussi les divers comptes rendus que James a publiés dans la presse d'œuvres de Gautier sont-ils empreints d'un même diagnostic, mais au jugement ambivalent: admiration pour «le poète du regard sur les choses» (p. 30), agacement devant son «imperturbable aménité morale» (p.81). Préfacés par Paolo Tortonese (pp.9-28), traduits par Emmanuel Saussier et Myriam Faten Sfar, ces articles sont désormais disponibles dans cette petite collection fort maniable des éditions Manucius, spécialisée dans les écrits peu accessibles de grands auteurs du xix ${ }^{e}$ siècle.

3 L'article Tableaux de siège: Paris, 1870-1871, paru dans «Nation», le 25 janvier 1872 (pp. 29-34), se penche sur les chroniques picturales consacrées par Gautier à la capitale et à Versailles au lendemain de la défaite et de la Commune. Le blâme dû aux circonstances traitées avec un brio qui lui paraît signe de légèreté est évident, même si la beauté picturale est reconnue. 
Quand, après le décès de Gautier, la «North American Review» lui demande pour avril 1873 d'examiner sa production dramatique, il consacre au Théâtre: mystère, comédies et ballets (pp. 35-75) une notice plus favorable, analysant sa perfection formelle. Étendant déjà largement son attention au reste de l'œuvre, notamment au Capitaine Fracasse, ce «conte de fées de la bohème, un triomphe du picaresque» (p. 66), il discerne la «tension pure et claire des accords mineurs» de Gautier (p.37). Son ton plein de «bonhomie païenne» l'étonne par la «sérénité aveugle de sa jouissance» (p.39). Mais l'extraordinaire faculté de distinction visuelle de cet Oriental égaré dans le monde occidental le séduit. Gautier aime à choisir soigneusement ses mots par l'emploi constant des dictionnaires, pratique l'énumération rabelaisienne avec le «délice grotesque de la quantité» (p.42). Chacune de ses phrases "constitue une vignette» (p. 50). Sa passion minutieuse du réel finit par lui donner «le relief finalement détaillé des accessoires et des perspectives d'une gravure d'A. Dürer» (pp. 57-58).

C'est pourquoi, à la parution de Théophile Gautier, souvenirs intimes, par Ernest Feydeau; Histoire du Romantisme, suivies de notices romantiques, etc par Théophile Gautier, il embrasse désormais l'œuvre tout entière, discernant son «génie» particulier pour la «North American Review», en octobre 1874 (pp. 77-95). Il admire notamment comment, toujours pauvre, Gautier a su, pour des articles de presse en fait alimentaires, ciseler en «prose exquise» (p. 78) sa critique picturale et théâtrale au point d'en faire une anecdotique mais intéressante histoire de l'art moderne. James s'insurge contre Ernest Feydeau, dont le portrait, nourri de fréquentation amicale, rapetisse en fait le talent qu'il veut réhabiliter. Et l'auteur américain d'opposer la «graine montée» (Feydeau, Flaubert et Dumas fils) à la "graine sauvage», plus forte à ses yeux, de la génération romantique (p. 83).

Quand sont traduits A Winter in Russia et Constantinople, James fait paraître dans la «Nation» deux recensions, les 12 novembre 1873 (pp.97-103) et 15 juillet 1875 (pp.105-109), qui déplorent la faiblesse du rendu des œuvres originales, sans doute inhérente au principe même de translation dans une autre langue. Il se contente pour le Voyage en Russie, correctement traduit par M. Ripley, de renvoyer au récit en français, charmant comme une symphonie sur le gel. Mais, pour le voyage oriental, il vitupère la désinvolture du traducteur, Robert Howe Gould, qui n'hésite pas à édulcorer par des épithètes vagues, des coupures ou des ajouts de son cru, même pas signalés, la force du texte originel. James reconnaît alors vraiment la fantaisie verbale puissante du prosateur incomparable en Gautier. 